\title{
Lomber dejenere disk hastalığı ve füzyonsuz teknikler ile tedavisi
}

\section{Lumbar degenerative disc disease and treatment with fusionless techniques}

\author{
H. Bahadır Gökçen, Sinan Erdoğan, Çağatay Öztürk
}

LIV Spine Center, LIV Hospital, Ulus, İstanbul

\begin{abstract}
Lomber omurganın dejeneratif disk hastalıkları sık görülür. İleri yaştaki bel ağrısının nedeni, sıklıkla dejeneratif disk hastalığıdır. Sinir basısı ile birlikte olan olgularda, radikülopati semptomları ön plandadır. Lomber dejeneratif disk hastalıkları tedavisinde, konservatif ve cerrahi tedavi yöntemleri kullanılabilir. Son yıllarda, cerrahi tedavi yöntemleri gelişme göstermiştir. Gelişen teknolojinin yardımı ile, füzyonsuz harekete izin veren sistemler popülarite kazanmıştır. Biyolojik çalışmalardaki gelişmeler, tedavi seçeneklerine heyecan verici bir bakış açısı getirmiştir. Gelecekte, füzyonsuz tedavi yöntemleri füzyonlu cerrahilerin yerini alacak gibi gözükmektedir.
\end{abstract}

Anahtar sözcükler: omurlararası disk dejenerasyonu; cerrahi tedavi, füzyonsuz
Degenerative disc disease of lumbar spine is seen frequently. Usually, the reason of low back pain at older age is degenerative disc disease. Radiculopathy symptoms are in the foreground in cases accompanying nerve compression. Conservative and surgical methods can be used as treatment options in lumbar degenerative disc disease. Surgical treatment options advanced during the last decade. Nonfusion systems have gained popularity with the help of developing technology. Due to the improvements in biological studies, treatment options have gained an exciting aspect. In the future, it seems like the treatment options without fusion will take the place of surgical treatments with fusion.

Key words: intervertebral disc degeneration; operative therapy, fusionless omber omurganın dejeneratif hastalığı oldukça sık görülür. Lomber omurganın hareketli yapısı, dejenerasyonun bu bölgede daha sık görülmesine neden olur. Disk yapılarındaki dejenerasyon, kendini zamanla artan ağrı ile gösterir. Herniye olan diskin sinir köklerine basısı, tamiri zor olan bir süreci başlatabilir. Bu hastalarda tedavi yaklaşımları, istirahatten cerrahi tedaviye kadar geniş bir yelpazeyi içerir. Tedavinin en alt basamağında yatak istirahati vardır. Ağrı kesici ilaç tedavisi, egzersiz ve lokal etkili steroid enjeksiyonları, konservatif tedavinin diğer basamaklarını oluşturur. Hastada ilerleyici nörolojik defisit olması, kauda ekina sendromu gelişmesi ve miyelopati bulgularının olması, cerrahi tedavi endikasyonudur.

Son 10 yılda, dejeneratif omurga hastalıklarının cerrahi tedavisi değişiklikler göstermiştir. Geleneksel olarak altın standart, "interbody" füzyonlu cerrahilerdir. Bu cerrahiler, \%60-90 arasında değişen başarılara sahip olup, anterior veya posterior yaklaşımlar ile uygulanabilmektedir. ${ }^{[1]} \mathrm{Bu}$ prosedürlerin, komşu segment hastalığı ve psödoartroz gibi olası komplikasyonlarının tanımlanması, spinal cerrahi ile uğraşan cerrahları, gelişen teknoloji yardımı ile, füzyonsuz yeni cerrahi teknikler geliştirmeye yönlendirmiştir.

Füzyonsuz tedaviler; total disk replasmanı, nükleus pulpozus replasmanı, pedikül bağımlı dinamik stabilizasyon cihazları, total faset eklem replasman sistemleri ve interspinöz sistemler olarak sınıflandırılabilir.

\section{NÜKLEUS PULPOZUS (NP) REPLASMANI}

NP replasmanı, füzyonsuz cerrahilerin en az invaziv olan girişimi olarak nitelendirilebilir. İleri düzeyde olmayan disk patolojilerinin tedavisinde kullanılabilen bir yöntemdir. Primer endikasyonu, altı aylık konservatif tedaviye cevap vermeyen semptomatik lomber diskojenik ağrıdır. Görüntüleme yöntemleri ile disk yüksekliğinin \%50'den fazla azalmadığının, Evre-1 spondilolistezisten daha ileri bir spondilolistezis ve "end-plate" boyunca disk herniyasyonunun olmadığının

- İletişim adresi: Op. Dr. H. Bahadır Gökçen, LIV Spine Center, LIV Hospital, Ulus, İstanbul

Tel: 0212 - 9998418 e-posta: bahadrgokcen@gmail.com

- Geliş tarihi: 17 Ağustos 2015 Kabul tarihi: 17 Ağustos 2015 

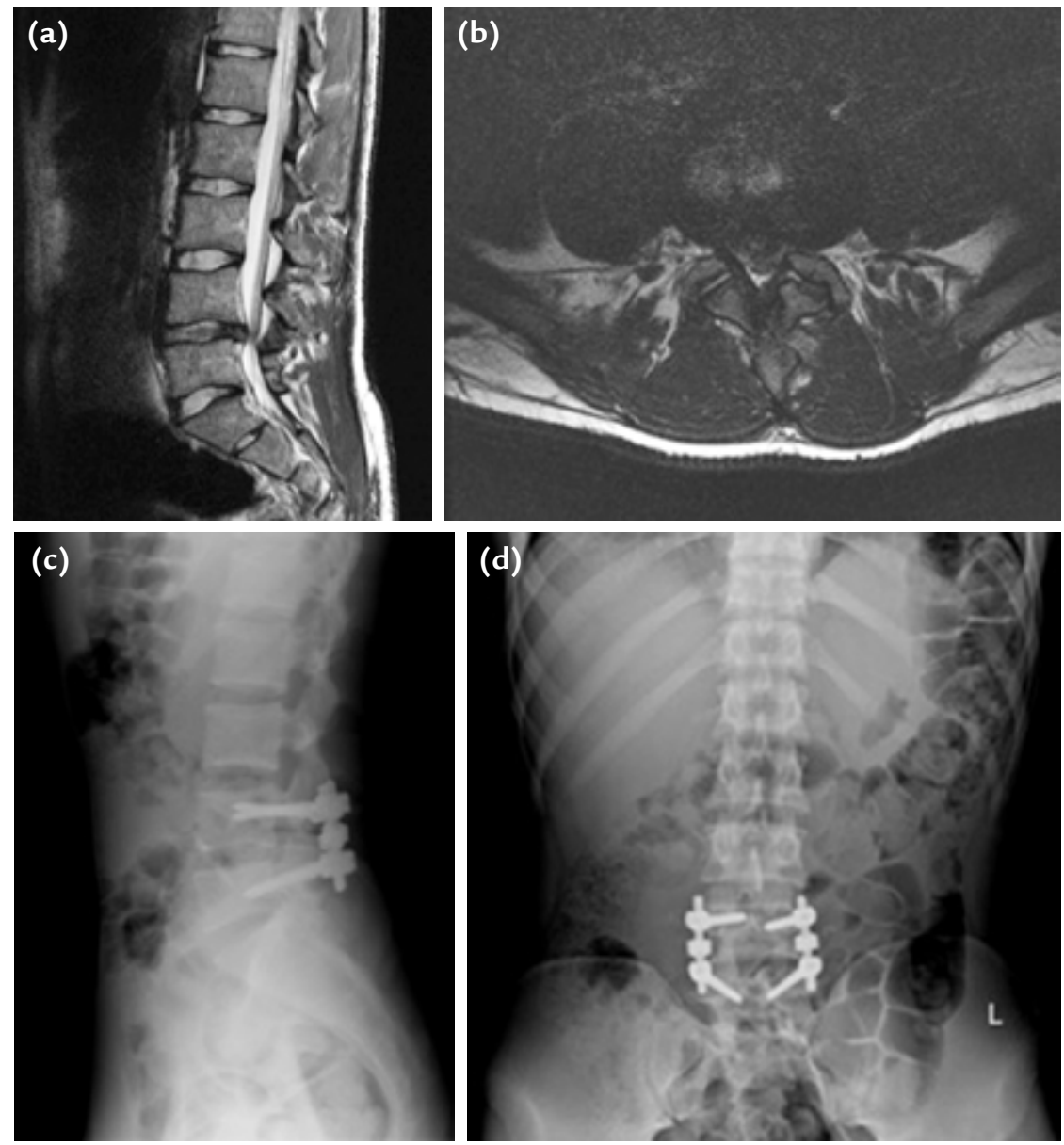

Şekil 1. a-d. L4-5 diskektomi sonrası dinamik sistem yapılmış hastanın ameliyat öncesi manyetik rezonans görüntüleri ve ameliyat sonrası çekilmiş direkt grafileri.

gösterilmesi gerekir. Literatürde, NP replasmanı yapılmış 423 hastanın klinik sonuçları ile ilgili bir çalışmada, implant tekniğindeki gelişme ve uygun hasta seçiminin klinik başarıyı arttırdığı ve implanta bağlı komplikasyon oranlarını düşürdüğü belirtilmiştir. ${ }^{[2]}$ İmplantın yerleştirilmesi için kullanılan cerrahi yaklaşım, implantın posteriora yer değiştirmesini etkileyebilir. Bu nedenle, literatürde, anterolateral transpsoas yaklaşımı ile yerleştirilen NP implantları bildirilmiştir. ${ }^{[3]}$

\section{INTERSPINÖZ CIHAZLAR}

Bu cihazlar, son zamanlarda, dejeneratif lomber omurga hastalıklarının tedavisinde artan bir öneme sahip olmuştur. Illk olarak, 20 yılı aşkın bir süre önce, Avrupa'da tanımlanmıştır. Çok daha az invaziv bir yöntem olması, çok az kemik rezeksiyonu gerektirmesi ve spinal kord ile ilintili gelişebilecek komplikasyonların olmaması, sistemin avantajlarıdır. Eşlik eden hastalıkları olan, yüksek riskli ve başka yöntemlerin kullanılamadığı hastalarda, az kan kaybı ve kısa anestezi süresi nedeniyle tercih edilebilir. Bu sistem, statik ve dinamik olarak iki şekilde sınıflandırılabilir. Statik sistemler, spinöz proses distraksiyonu yaparak etki eder. Ciddi stenozu olan olgularda, mikro-cerrahi ile yapılan dekompresyonun yerini tutmadığı, fakat seçilmiş hastalarda güvenilir, efektif ve minimal invaziv bir işlem olduğu bildirilmiştir. ${ }^{[4]}$

\section{PEDIKÜL BAĞIMLI DINAMIK STABILIZASYON CIHAZLARI}

Bu cihazların kullanımı ve endikasyonları geniş bir yelpazede sıralanabilir. Diskojenik kökenli ağrıların tedavisinde kullanılabilir. Anormal yük dağııımı, lomber bölgede osteoartritik değişikliklerin nedeni olarak bilinir. Bu yük dağılımının disk üzerine de olumsuz etkileri vardır. Dinamik stabilizasyon sistemleri, disk kaynaklı ağrılarda harekete izin vererek, anormal yük dağılımını değiştirmeyi amaçlar (Şekil 1). 

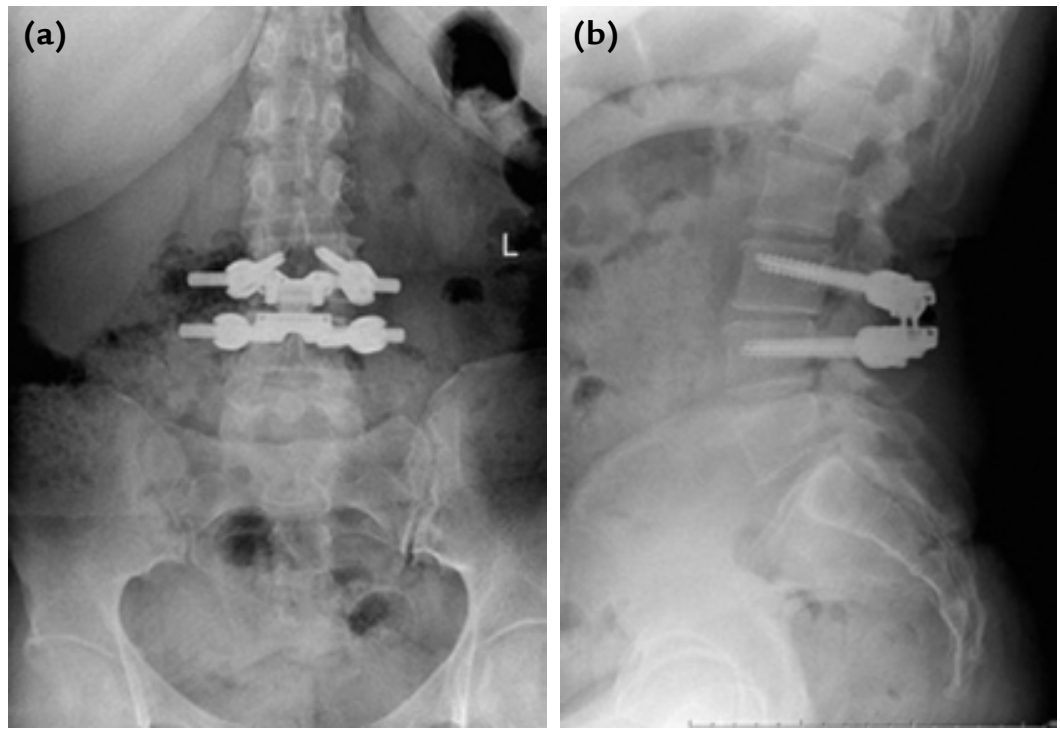

Şekil 2. a, b. L3-4 laminektomi ve bilateral fasetektomi sonrası "TOPS" görüntüsünün direkt grafileri.

Birçok sistem, bunu sağlamak amacıyla üretilmiş ve kullanılmıştır. Literatürde, lomber fasetleri ekstansiyon pozisyonunda kilitleyerek, kısıtlı fleksiyona imkan veren sistemler tanımlanmıştır. ${ }^{[5]}$ Füzyon yapılan hastalar ile bu sistemin karşılaştırıldığı bir yayında, sistemin füzyonlu cerrahiye göre daha kötü klinik sonuçlar verdiğinden bahsedilmiştir. ${ }^{[6]}$

Dinamik sistemleri, instabilitenin eşlik ettiği lomber dejeneratif disk hastalıkları tedavisinde kullanmak, sistemin etki mekanizmasıyla bağdaşmaz. Dejeneratif lomber disk hastalığı olan olgularda instabilitenin varlığı, dinamik sistem kullanımı sonrası klinik sonuçları olumsuz etkileyebilir. Bu nedenle, dinamik sistem kullanımında instabilite varlığının araştırılması çok önemlidir.

Dinamik sistemler, dekompresyon cerrahisi uygulanmış dejeneratif disk hastalarında posterior tansiyon bandını koruma amacıyla kullanılabilir. Sadece dekompresyon yapılan olgulara göre, klinik sonuçları daha iyidir. ${ }^{[7,8]}$

\section{TOTAL FASET EKLEM REPLASMAN SISTEMLERi}

$\mathrm{Bu}$, lomber dejeneratif hastalıkların tedavisinde kullanılan yeni ve gelişmekte olan bir diğer sistemdir. Komplet laminektomi ve fasetektomi sonrası, fonksiyonel faset eklem yapısını restore etmek amacıyla kullanılabilir. Esas endikasyonu, lomber santral kanal ve "lateral reses" darlığına nörojenik kladikasyonun ve/ veya radikülopatinin eşlik ettiği, geniş dekompresyon gerektiren olgulardır. Geniş dekompresyon sonrası iyatrojenik olarak gelişebilen instabilite riskini azaltmayı amaçlar. Ayrıca, hareketi koruyarak füzyon ihtiyacını ortadan kaldırır. Total Faset Artroplasti Sistemi (TFAS) ve Total Posterior Element Sistemi (TOPS) adıyla kullanılan iki adet sistem bulunmaktadır (Şekil 2).

Spinal stenoz ve spondilolistezisin eşlik ettiği dejeneratif hastalıkta, TOPS sisteminin klinik düzelmeyi ve radyolojik stabiliteyi sağladığı bildirilmiştir. ${ }^{[9]}$

\section{TOTAL DISK REPLASMANI}

$\mathrm{Bu}$ yöntem, son yıllarda popülarite kazanmıştır. Hastalıklı disklerin yerine yapay diskler yerleştirilerek, hareket kaybının engellenmesi amaçlanır. Füzyon ile karşılaştırılınca, teorik olarak daha az komşu segment hastalığı görülmesi, bu sistemin avantajı olarak değerlendirilebilir. Paraspinal adalelerin sıyrılmasını gerektirmemesi ve füzyon olmadığı için psödoartrozun da görülme riskinin olmaması, diğer avantajları olarak sayılabilir. Fakat, bazı olası dezavantajları da bulunmaktadır. Anterior yaklaşımla ilgili kas atonisi, damar zedelenme riski, üretral zedelenme, retrograd ejakülasyon, uzamış ileus ve inguinal herni, gelişebilecek komplikasyonlar arasında sayılabilir.

Revizyon cerrahisi gerektiğinde bu risklerin daha da artmış olması, bu sistemin kullanımını düşündürücü kılar. Yapılan çalışmalarda, total disk artroplastisinin kısa dönem sonuçlarının füzyonlu cerrahiye bir üstünlüğü olmadığı bildirilmiştir. ${ }^{[10-13]}$ 
Literatürde, dejeneratif disk hastalığı ile birlikte herniye nükleus pulpozusu olan olgularda uygulanan total disk artroplastisinin, sadece dejenere disk hastalığı olan olgulara göre daha etkili olduğu ve L4-5 ile L5-S1 arasında daha iyi sonuçlar verdiği belirtilmiştir. ${ }^{[14-15]}$

Spinal implant teknolojilerindeki gelişme ve büyüme potansiyeli şaşırtıcıdır. Yeni mekanik cihazların ve cerrahi yaklaşımların gelişmesinden öte, dejeneratif omurga hastalıklarının tedavisinde kullanılabilecek olan biyolojik yaklaşımların geliştirilmesi de son derece heyecan vericidir.

Dejenerasyonun erken sürecinde, IGF-1, OP-1, TGF-ß1, EGF ve ßFGF gibi büyüme faktörlerinin enjeksiyonu, tedavi edici özelliği olan proteoglikan sentezi ve ekstrasellüler matriksi arttırıcı etkiye sahip olabilir. Disk dejenerasyonundan korunmada, gen terapisi kullanımı bazı pozitif sonuçlar göstermiştir. ${ }^{[16]}$

\section{SONUÇ}

Lomber dejeneratif hastalıklarda kullanılan her sistemin, kendine göre avantajı ve dezavantajı bulunmaktadır. Füzyonsuz tedavilerin giderek popüler olması, bu sistemlerin kullanım alanlarını da genişletmiştir. Kullanılacak sistemin endikasyonlarının doğru belirlenmesi, komplikasyon oranını düşürmede önemlidir. Dejeneratif lomber disk hastalıklarının tedavisinde, füzyonsuz sistemlerin başarılı bir alternatif tedavi yöntemi olduğunu düşünmekteyiz. Yapılan biyolojik çalışmaların da, bu gibi dejeneratif hastalıkların tedavisine farklı bir bakış açısı getireceğine inanmaktayız.

\section{KAYNAKLAR}

1. O'Beirne J, O'Neill D, Gallagher J, Wiiliams DH. Spinal fusion for back pain: a clinical and radiological review. J Spinal Disord 1992;5(1):32-8.

2. Klara PM, Ray CD. Artificial nucleus replacement: clinical experience. Spine (Phila Pa 1976) 2002;27(12):1374-7.

3. Bertagnoli R, Vazquez RJ. The Anterolateral TransPsoatic Approach (ALPA): a new technique for implanting prosthetic disc-nucleus devices. J Spinal Disord Tech 2003;16(4):398-404.
4. Kuchta J, Sobottke R, Eysel P, Simons P. Two-year results of interspinous spacer (X-Stop) implantation in 175 patients with neurologic intermittent claudication due to lumbar spinal stenosis. Eur Spine J 2009;18(6):823-9. CrossRef

5. GrafH. Lumbar instability: surgical treatment without fusion. Rachis 1992;412:123-37.

6. Hadlow SV, Fagan AB, Hillier TM, Fraser RD. The Graf ligamentoplasty procedure. Comprasion with posterolateral fusion in the management of low back pain. Spine (Phila $\mathrm{Pa}$ 1976) 1998;23(10):1172-9.

7. Schwarzenbach O, Stoll TM, Dubois GG. Dynesys: the dynamic neutralization system for the spine. In: Corbin TP, Connoly PJ, Yuan HA, et al., editors. Evidence and framework for evaluating new technology. St. Louis, MO: Quality Medical Publishing, Inc; 2006. p.485-500.

8. Schnake KJ, Schaeren S, Jeanneret B. Dynamic stabilization in addition to decompression for lumbar spinal stenosis with degenerative spondylolisthesis. Spine (Phila Pa 1976) 2006;31(4):442-9.

9. Anekstein $Y$, Floman $Y$, Smorgick $Y$, Rand $N$, Millgram $M$, Mirovsky Y. Seven years follow-up for total lumbar facet joint replacement (TOPS) in the management of lumbar spinal stenosis and degenerative spondylolisthesis. Eur Spine J 2015. [Epub ahead of print]

10. McAffee PC, Fedder IL, Saiedy S, Shucosky EM, Cunningham BW. SB Charite disc replacement: report of 60 prospective randomized cases in US center. J Spinal Disord Tech 2003;16(4):424-33.

11. Möller $\mathrm{H}$, Hedlund R. Surgery versus conservative management in adult isthmic spondilolisthesis -a prospective randomized study part 1. Spine (Phila Pa 1976) 2000;25(13):1711-5.

12. Ogilvie JW, Schendel M. Comprasion of lumbosacral fixation devices. Clin Orthop Relat Res 1986;(203):120-5.

13. Zdeblick TA. A prospective, randomized study of lumbar fusion. Preliminary results. Spine (Phila Pa 1976) 1993;18(8):983-91.

14. Siepe CJ, Mayer HM, Henz-Leisenheimer M, Korge A. Total lumbar disc replacement: different results for different levels. Spine 2007;32(7):782-90.

15. Siepe CJ, Mayer HM, Wiechert K, Korge A. Clinical results of total lumbar disc replacement with ProDisc II: threeyear results for different indications. Spine (Phila Pa 1976) 2006;31(17):1923-32.

16. Bridwell KH, DeWald RL. Textbook of Spinal Surgery. 3rd ed. OvidSP: Lippincott Williams \& Wilkins; 2011. 